Relations industrielles

Industrial Relations

\title{
Alter, Norbert, Sociologie de l'entreprise et de l'innovation
}

\section{Mircea Vultur}

Volume 52, numéro 3, 1997

URI : https://id.erudit.org/iderudit/051193ar

DOI : https://doi.org/10.7202/051193ar

Aller au sommaire du numéro

Éditeur(s)

Département des relations industrielles de l'Université Laval

ISSN

0034-379X (imprimé)

1703-8138 (numérique)

Découvrir la revue

Citer ce compte rendu

Vultur, M. (1997). Compte rendu de [Alter, Norbert, Sociologie de l'entreprise et de l'innovation]. Relations industrielles / Industrial Relations, 52(3), 658-659.

https://doi.org/10.7202/051193ar

Tous droits réservés (C Département des relations industrielles de l'Université Laval, 1997
Ce document est protégé par la loi sur le droit d’auteur. L’utilisation des services d'Érudit (y compris la reproduction) est assujettie à sa politique d'utilisation que vous pouvez consulter en ligne.

https://apropos.erudit.org/fr/usagers/politique-dutilisation/ 


\section{Sociologie de l'entreprise et de l'innovation}

par Norbert ALTER, Paris : Presses universitaires de France, 1996, 241 p., ISBN 2-13-047491-8.

Depuis plusieurs années, les problématiques organisationnelles, intégrées dans un champ d'analyse multidisciplinaire, s'imposent largement dans les travaux de recherche en sciences sociales aussi bien chez les sociologues que chez les économistes ou les politistes.

Dans ce contexte, l'ouvrage de Nobert Alter, La sociologie de l'entreprise et de l'innovation, apparait comme le produit d'une compréhension de l'état actuel des choses dans les études sur l'entreprise en tant que lieu de rationalité économique et qu'univers de socialisation. Le titre souligne d'emblée l'ambition de l'auteur. Sur un sujet beaucoup questionné, Alter propose un nouvel éclairage. À partir des enseignements que d'autres analyses délivrent, il dégage une série de propositions d'ordre descriptif, qui par la rigueur de leur articulation inscrivent ce travail parmi les études les plus brillantes dans ce domaine.

Au niveau de la construction interne du livre, les sujets abordés sont insérés dans une logique remarquable. Dans un premier temps, l'auteur analyse les modalités de transformations des entreprises dans un cadre théorique visant à offrir une meilleure compréhension des capacités dont disposent celles-ci pour faire face aux changements dans une situation d'innovation (concept défini à la manière de Schumpeter comme la réalisation des combinaisons nouvelles entre les différentes ressources d'une entreprise). L'explication de ces capacités de transformation, d'adaptation au changement, est réalisée dans des perspectives différentes. Premièrement, on accorde priorité aux contraintes de l'environnement sur la structure fonctionnelle, dans un milieu économique d'incertitude où la logique de l'innovation impose un modèle d'organisation de l'entreprise qui ne repose plus sur les principes tayloriens. En seconde lieu, l'explication privilégie l'analyse des jeux des acteurs et définit les capacités de transformation des entreprises par l'émergence d'ententes nouvelles au niveau des opérateurs. Dans ce cadre, l'auteur s'intéresse aussi aux modalités d' "apprentissage collectif ", c'est-à-dire à « la façon dont les relations de pouvoir, et les conflits, définissent l'élaboration de nouveaux " construits sociaux " assurant l'évolution de l'organisation et son efficacité ». L'association du concept d'acteur avec celui de culture (pour mettre en évidence la dimension contraignante des valeurs et des normes dans les capacités collectives à changer) et la transformation des représentations (objet de l'approche cognitiviste) deviennent, dans la démarche de l'auteur, d'autres éléments explicatifs relatifs aux capacités de changement des entreprises dans un univers de travail caractérisé par l'innovation.

L'analyse d'Alter rapproche ces quatre perspectives et leur prête une unité de démarche conceptuelle. « Un changement ou une innovation ne supposent-ils pas en effet, pour être effectifs, de correspondre à des contraintes d'environnement, lesquelles sont prises en compte par des acteurs à la fois intéressés et définis par leur culture, et inscrits dans des processus cognitifs assurant une plus grande capacité dans le rapport à l'idée même d'entreprise? " Comme Boudon au niveau de la société globale, Nobert Alter cherche à mettre en évidence les mobiles de l'action (les "bonnes raisons ") dans un univers organisé, en les présentant comme le résultat d'un agencement spécifique entre culture, pouvoir, logique économique et innovation. Le principe qui se dégage est que "l'action collective, qu'elle soit définie à partir du calcul, de la culture d'appartenance ou de l'identité collective, n'est pas incompatible avec l'idée de rationalité économique. Au contraire, l'idée même d'entreprise, 
d'entrepreneuriat, repose sur cette articulation, inattendue du point de vue des principes classiques de gestion. "

L'analyse de la crise du travail et des concepts de crise ouvre des perspectives novatrices sur la compréhension des rationalités économiques dans un monde dominé par la recherche permanente de l'efficacité, et fait surgir un regard critique par rapport au fonctionnement de l'entreprise. L'ouvrage apporte également une vision globale sur les relations existantes entre entreprise et culture ainsi que sur le rapport innovation/tradition. Ayant comme point de départ L'éthique protestante de Weber (où l'interprétation de l'auteur tombe dans le "piège à rat " popperienne en présentant les thèses de sociologue allemand concernant la relation éthique de travail/organisation économique comme un renversement du matérialisme marxiste), l'analyse s'inscrit dans une branche conceptuelle qu'on peut appeller selon les mots de l'économiste Michio Morishima " éthologie ", en ce qu'elle met en évidence les liaisons qui existent entre les valeurs et les principes dominants du système social et les formes de l'action économique.

Nobert Alter a réussi ainsi à faire une présentation à la fois synthétique et détaillée d'une série de questions dont les contours demeurent encore mal définis, bien que leur opérationalisation dans les études témoigne de leur extrême effectivité dans la réalité sociale. Dans ce cadre, la normativité de la démarche s'impose comme une condition sine qua non. "Les recherches combinant la sociologie et l'économie ne sont pas [...] qu'un effort de pluridisciplinarité strictement académique : elles permettent d'avancer concrètement dans la compréhension des logiques habitant les entreprises, en s'in- terrogeant sur la capacité à trouver des formes de coopération durables. "Le propos d'Alter parvient ainsi à un niveau d'intelligibilité du réel, des théories économiques et de l'organisation qui dépasse tant la vision étroite d'un homo œconomicus taylorien que l'utilitarisme stéréotypé incapable de saisir l'acteur social dans un cadre soumis en permanence à des modifications endogènes et exogènes. L'effort conceptuel à la base d'une lecture des références premières dans le domaine rend intelligible et mieux compréhensible la réalité contingente des organisations.

L'ouvrage "prend appui sur des conceptions contrastées, parfois polémiques, élaborées par le milieu scientifique ", la littérature discutée est nouvelle et les arguments de l'auteur sont insérés dans une matière bien connue. De ce point de vue, le livre d'Alter contribue concrètement au cumul des connaissances sur les phénomènes organisationnels et sur la dynamique de l'action organisée.

Cette présentation n'épuise pas, tant s'en faut, un livre assez riche. La multiplicité des pistes ouvertes, la rigueur de la construction, l'autorité d'un raisonnement s'appuyant sur une impeccable culture sociologique et économique en font d'emblée un ouvrage de référence essentiel pour quiconque s'intéresse à l'avenir de notre société. Excellent instrument de travail dans le domaine de l'analyse des entreprises, à conseiller à tout étudiant ou spécialiste qui désirerait avoir une approche claire des différents concepts et modèles élaborés ces dernières années en la matière.

MIRCEA VULTUR Université Laval 